\title{
Skin immunoglobulin deposition following intravenous immunoglobulin therapy in toxic epidermal necrolysis
}

\author{
Paquet P, Kaveri S, Jacob E, Pirson J, Quatresooz P, Piérard GE. Skin \\ immunoglobulin deposition following intravenous immunoglobulin \\ therapy in toxic epidermal necrolysis. \\ Exp Dermatol 2006: 15: 381-386. (C) 2006 The Authors. \\ Journal compilation (C) 2006 Blackwell Munksgaard
}

Abstract: Human intravenous immunoglobulins (IVIg) which contain anti-CD95 antibodies have been proposed to treat toxic epidermal necrolysis (TEN). Presently, there is no evidence that IVIg reach the keratinocytes in TEN patients. The aim of this study was to assess the Ig distribution in the serum, blister fluid and skin of six consecutive TEN patients treated with IVIg $(1 \mathrm{~g} / \mathrm{kg} /$ day $)$ for 3 days. They were compared with five TEN patients who only received supportive therapy. In all patients, $\operatorname{IgA}$, IgM and $\operatorname{IgG}$ concentrations were measured in the serum and blister fluid using an immuno-nephelometric method.

Immunohistochemistry was performed on skin biopsies taken from both TEN clinically involved and uninvolved skin to search for IgG deposits. On admission, the IgG concentrations were significantly higher in both TEN serum and TEN blister fluid compared with their respective IgA and IgM contents. The IgG, IgA and IgM concentrations in blister fluid were significantly lower than their respective serum concentrations. The serum and blister fluid $\operatorname{IgG}$ concentrations, but not that of $\operatorname{IgA}$ and IgM, were markedly increased at the completion of the IVIg treatment. By contrast, they remained unchanged in the TEN patients that were untreated with IVIg. In the IVIg-treated patients, the IgG intraepidermal deposits raised markedly in both TEN-involved and uninvolved skin. This was not the case in patients who did not receive IVIg. These results suggest that IVIg perfusions brought a prominent increase in $\mathrm{IgG}$ concentration in the serum, blister fluid and epidermis of both TEN-involved and clinically uninvolved skin. The presence of potentially protective IgG in TEN epidermis following IVIg treatment could help limiting the disease progression.

\author{
P. Paquet $^{1}$, S. Kaveri ${ }^{2}$, \\ E. Jacob ${ }^{2,3}$, J. Pirson ${ }^{2,3}$, \\ P. Quatresooz ${ }^{1}$ and \\ G. E. Piérard ${ }^{1}$ \\ ${ }^{1}$ Department of Dermatopathology, University \\ Hospital of Liège, Liège, Belgium; \\ ${ }^{2}$ INSERM, Unité 681, Paris, France; \\ ${ }^{3}$ Brussels Military Hospital, Brussels, Belgium
}

Key words: toxic epidermal necrolysis immunoglobulins

Dr Philippe Paquet

Department of Dermatopathology

CHU Sart Tilman

B-4000 Liège

Belgium

Tel: +3243662408

Fax: +3243662976

e-mail: p.paquet@chu.ulg.ac.be

Accepted for publication 8 February 2006

\section{Introduction}

Toxic epidermal necrolysis (TEN) is a rare disease characterized by extensive destruction of the epidermis. The mortality rate averages $25-30 \%$ due to septicemia and metabolic changes following the loss of epidermal integrity. The generally recognized cause of TEN is an adverse drug reaction resulting from the specific formation of toxic drug metabolites, probably in the skin itself. The reactive drug metabolite(s) exert(s) cytotoxic effects on keratinocytes. This event is thought to be mediated by the combination of an increase in $\mathrm{Ca}^{2+}$ intracellular pool, the formation of reactive oxygen species (ROS) including nitric oxide
(NO) and the activation of both the CD95 and the TNF-a systems $(1,2)$. An active role has also been ascribed to $\mathrm{T}$ lymphocytes, particularly CD8+ and NK cells in the epidermis (3). Macrophages Factor XIIIa+ dendrocytes also appear to play some pathogenic role in the epidermis and dermis (4). Complex interactions link these cytotoxic effects leading to massive apoptosis in keratinocytes (1).

The current TEN treatments combine supportive and antiseptic measures. It is recognized that systemic corticosteroids worsen the prognosis by increasing the risk of septicemia if given for more than $48 \mathrm{~h}$ (5). Only few TEN cases have been 


\section{Paquet et al.}

treated so far with other drugs, including cyclophosphamide, pentoxifylline, thalidomide and ciclosporin A (1). A few years ago, another therapeutic approach based on the administration of high dosages of intravenous immunoglobulins (IVIg) was proposed to treat TEN patients (6). The rationale for this treatment was to block CD95 (Fas), a cell-surface receptor initiating keratinocyte apoptosis in TEN (6). Commercially available IVIg perfusions consist of Ig prepared from pooled human plasma (7). They typically contain more than $95 \%$ IgG presenting functionally intact Fc-dependent effector functions, admixed with low amounts of $\operatorname{IgA}$ and $\operatorname{IgM}(7)$. The clinical outcome following IVIg treatment of TEN remains controversial, showing improvement or not, in morbidity and mortality $(6,8-13)$.

Conceptually, failure of IVIg treatment in TEN may result from low bioavailability of the protective $\mathrm{IgG}$ in the altered skin. This aspect was never explored until now. Using immunochemistry, we looked for the presence of $\mathrm{IgG}$ in TEN skin before and after a 3-day IVIg treatment. A control group was composed of patients treated with supportive measures only. We also measured the evolution of the Ig concentrations in the serum and blister fluid in the same IVIg-treated and control TEN patients.

\section{Materials and methods}

\section{Patients}

Six patients (four women and two men, mean age 47 years) with TEN diagnosed following defined clinical criteria (14) were enrolled in the study (TEN patients). A recent drug intake was reported in each case. The most probable culprit drug was identified following an imputability method used for toxic drug reactions. The salient clinical characteristics of the TEN patients are presented in Table 1. At baseline, that is before any specific treatment, TEN blister fluid was collected from taut lesions of less than $24 \mathrm{~h}$ in duration. After centrifugation, the liquid was stored at $-20^{\circ} \mathrm{C}$ until testing. Serum was simultaneously collected and processed following the same procedure. In each patient, a 4-mm punch biopsy was performed in a recent $(<24 \mathrm{~h})$ blister and in the apparently uninvolved skin at least $2 \mathrm{~cm}$ apart from a bullous or erythematous lesion. The patients were placed on fluidized beds and benefited from supportive and antiseptic care measures including daily baths. IVIg (Multigam ${ }^{\mathbb{R}}$, CAF-DCF/Belgian Red Cross) was administered daily at a dose of $1 \mathrm{~g} / \mathrm{kg} /$ body weight for 3 days. The IVIg batches were not tested for their Ig content.

At completion of the treatment, cutaneous biopsies were obtained close to the first biopsy sites. Serum and blister fluid were sampled again. Blister fluid was only collected in two patients, because blisters were dried or punctured in the other four.

These samples were compared with similar biological samples obtained from five other TEN patients (three women and two men, mean age 45 years) stored since the mid nineties (TEN controls), a time when IVIg were not used in TEN. These control patients had received supportive care only, without any drug considered active in TEN, especially IVIg (Table 1).

\section{Ig concentration measurement}

$\operatorname{IgA}, \operatorname{IgG}$ and $\operatorname{IgM}$ concentrations were assessed in the serum and blister fluid samples using immuno-nephelometry with $\mathrm{N}$ antisera to human Ig (Dade Behring, Marburg, Germany) (15). Data were expressed in $\mathrm{g} / \mathrm{l}$ and recorded as medians and ranges.

The paired non-parametric Friedman test was performed as a single overall test to search for differences among $\operatorname{IgG}, \operatorname{IgA}$ and IgM concentrations in the samples of both the serum and the blister fluid obtained at baseline. The Dunn's multiple comparison test was performed as a second test if variations were significantly greater than expected by chance. The Wilcoxon test was used for paired data about the Ig concentrations in TEN serum and blister fluid. A $P$-value lower than 0.05 was considered significant.

\section{Immunohistochemistry}

Biopsies were formalin-fixed for about $24 \mathrm{~h}$ and paraffinembedded. Serial sections were cut and processed for standard microscopy and immunohistochemistry $(16,17)$. The three-step avidin-biotin method was applied to a mouse antihuman IgG monoclonal antibody (Dakocytomation, Glostrup, Denmark) used at a $1: 3000$ dilution for a 10-min incubation. The intensity of IgG-positive immunoreactivity present in a pemphigus-like pattern was rated on a 5 -grade scale $(0$, absent; 1 , minimal; 2 , moderate; 3, dense; 4, widespread). Diffuse intrakeratinocyte deposits indicating a non-specific cell damage were not taken

Table 1. Characteristics of toxic epidermal necrolysis patients

\begin{tabular}{|c|c|c|c|c|}
\hline $\begin{array}{l}\text { Patients IVlg } \\
\text { or control (C) }\end{array}$ & $\begin{array}{l}\text { Age (years) } \\
\text { and sex }\end{array}$ & $\begin{array}{l}\% \text { of affected body areas } \\
\text { and outcome (A, alive; } D \text {, death) }\end{array}$ & $\begin{array}{l}\text { Duration of the disease } \\
\text { at sampling (days) }\end{array}$ & Probable culprit drug \\
\hline 1-IVlg & $43, \mathrm{~F}$ & $80 \mathrm{~A}$ & 4 & Amoxicillin + clavulanid acid \\
\hline 2-IVIg & $43, \mathrm{M}$ & $50 \mathrm{~A}$ & 7 & Telithromycine \\
\hline 3-IVIg & $47, \mathrm{~F}$ & $60 \mathrm{~A}$ & 7 & Indapamide \\
\hline 4-IVlg & $18, M$ & $60 \mathrm{~A}$ & 4 & Sertaline \\
\hline 5 -IVlg & $78, \mathrm{~F}$ & $50 \mathrm{D}$ & 3 & Amoxicillin \\
\hline $6-\mathrm{IVIg}$ & $51, \mathrm{~F}$ & $75 \mathrm{~A}$ & 8 & Allopurinol \\
\hline $7-\mathrm{C}$ & $32, \mathrm{~F}$ & $64 \mathrm{~A}$ & 4 & Ibuprofen \\
\hline $8-C$ & $56, \mathrm{~F}$ & $30 \mathrm{D}$ & 5 & Oxacillin \\
\hline $9-\mathrm{C}$ & $20, M$ & $40 \mathrm{D}$ & 2 & Maxipim or amikacin or vancomycin \\
\hline $10-C$ & $50, \mathrm{M}$ & $80 \mathrm{~A}$ & 2 & Naproxen \\
\hline $11-\mathrm{C}$ & $66, \mathrm{~F}$ & $60 \mathrm{D}$ & 6 & Phenytoin \\
\hline
\end{tabular}


into consideration. For each group (IVIg-treated and TEN control patients, TEN-involved and clinically uninvolved skin), a mean epidermal score was established for the IgG deposits. Patient 3 suffering from lupus erythematosus was not considered in the immunohistochemical study. Appropriate positive (pemphigus vulgaris, bullous pemphigoid, lupus erythematosus) and negative controls (normal skin, superficial burns, junctional epidermolysis bullosa) were used for assessing the $\mathrm{IgG}$ deposits in the skin tissues.

\section{Results}

\section{Ig concentration measurements}

The storage duration of the samples was much shorter in IVIg-treated patients than in TEN control patients. This might introduce a bias in the data. Hence, a comparison was made at first between baseline data of both groups of patients. It appeared that longer sample storage markedly decreased the detected IgG and IgA levels in both the serum and the blister fluid. This precluded any sound comparisons between the posttreatment data gained in the two groups of patients.

Upon pooling all baseline data, IgG concentrations were significantly higher $(P<0.0001)$ than the $\operatorname{IgA}$ and $\operatorname{IgM}$ concentrations in both the serum and the blister fluid (Table 2). The blister fluid concentrations of all Ig types were significantly $(P<0.01)$ lower than their respective serum concentrations (Table 2).

At the completion of the IVIg treatment, the median $\operatorname{IgG}$ serum concentration was markedly increased compared with baseline (Tables 2 and 3). By contrast, it remained similar in the TEN control patients (Tables 2 and 3). The IgA and IgM serum concentrations also remained nearly unchanged in the IVIg-treated group indicating

Table 2. Immunoglobulin concentrations $(\mathrm{g} / \mathrm{l})$ in toxic epidermal necrolysis (TEN) serum and blister fluid on patient admission

\begin{tabular}{|c|c|c|c|c|c|c|}
\hline \multirow[b]{2}{*}{ Patients } & \multicolumn{2}{|l|}{$\lg G$} & \multicolumn{2}{|l|}{$\lg A$} & \multicolumn{2}{|l|}{$\lg M$} \\
\hline & Serum & Blister & Serum & Blister & Serum & Blister \\
\hline \multicolumn{7}{|c|}{ IVIg-treated } \\
\hline 1 & 4.7 & 1.46 & 1.08 & 0.28 & 0.37 & 0.1 \\
\hline 2 & 19 & 6.36 & 2.52 & 0.94 & 0.62 & 0.2 \\
\hline 3 & 23.3 & 4.9 & 2.56 & 0.53 & 1.24 & 0.22 \\
\hline 4 & 18.9 & 3.57 & 1.03 & 0.14 & 0.50 & 0.06 \\
\hline 5 & 12 & 1.01 & 1.99 & 0.17 & 0.4 & 0.04 \\
\hline 6 & 13.5 & 2.99 & 3.74 & 0.99 & 0.57 & 0.4 \\
\hline Median & 16.20 & 3.28 & 2.25 & 0.40 & 0.53 & 0.15 \\
\hline \multicolumn{7}{|l|}{ Controls } \\
\hline 7 & 4.87 & 1.34 & 1.23 & 0.26 & 0.78 & 0.18 \\
\hline 8 & 3.73 & 0.46 & 0.92 & 0.06 & 1.63 & 0.09 \\
\hline 9 & 13.7 & 1.15 & 0.86 & 0.08 & 0.18 & 0.04 \\
\hline 10 & 10.9 & 1.96 & 2.58 & 0.28 & 3.34 & 0.25 \\
\hline 11 & 2.15 & 0.63 & 0.49 & 0.06 & 0.07 & 0.04 \\
\hline Median & 4.87 & 1.15 & 0.92 & 0.08 & 0.78 & 0.09 \\
\hline
\end{tabular}

Table 3. Immunoglobulin (Ig) concentrations ( $\mathrm{g} / \mathrm{l})$ in toxic epidermal necrolysis (TEN) serum and blister fluid after a 3-day disease evolution

\begin{tabular}{|c|c|c|c|c|c|c|}
\hline \multirow[b]{2}{*}{ Patients } & \multicolumn{2}{|l|}{$\lg G$} & \multicolumn{2}{|l|}{$\lg A$} & \multicolumn{2}{|l|}{$\lg M$} \\
\hline & Serum & Blister & Serum & Blister & Serum & Blister \\
\hline \multicolumn{7}{|l|}{ IVlg-treated } \\
\hline 1 & 37.2 & - & 2.8 & - & 0.3 & - \\
\hline 2 & 21.8 & - & 4.35 & - & 0.19 & - \\
\hline 3 & 44.3 & - & 2.79 & - & 0.71 & - \\
\hline 4 & 14.3 & 10.5 & 0.62 & 0.56 & 0.94 & 0.32 \\
\hline 5 & 28.6 & - & 3.53 & - & 0.82 & - \\
\hline 6 & 19.5 & 11.9 & 2.4 & 1.38 & 0.36 & 0.12 \\
\hline Median & 25.2 & & 2.59 & & 0.53 & \\
\hline \multicolumn{7}{|l|}{ Controls } \\
\hline 7 & 4.77 & 0.89 & 1.33 & 0.19 & 0.72 & 0.07 \\
\hline 8 & 4.59 & - & 1.23 & - & 1.68 & - \\
\hline 9 & 14.6 & - & 1.2 & - & 0.7 & - \\
\hline 10 & 11.35 & - & 2.04 & - & 3.42 & - \\
\hline 11 & 5.49 & 2.15 & 1.37 & 0.49 & 0.99 & 0.07 \\
\hline Median & 5.49 & & 1.33 & & 0.99 & \\
\hline
\end{tabular}

the lack of IgA and IgM supply by the IVIg perfusions. In the control group, both the IgA and the $\operatorname{IgM}$ serum concentrations were also unmodified after 3 days of disease evolution. Only two blister fluid samplings were available for comparison in each patient group (Table 4). The IgG concentration in blister fluid was markedly increased following the IVIg treatment, while it remained unchanged in the two control patients. The IVIg perfusions did not supply the blister fluid with IgA and IgM (data not shown). The IgA and IgM blister fluid concentrations also remained nearly unchanged in the control patients (data not shown).

\section{Immunohistochemistry}

In both groups of TEN patients, some intracytoplasmic IgG immunolabeling was present in clustered keratinocytes. This aspect indicating cell damage was not scored.

At baseline, the mean score of IgG deposits in a pemphigus-like pattern was discretely higher in

Table 4. IgG dosages and scoring in toxic epidermal necrolysis (TEN) patients

\begin{tabular}{|c|c|c|c|c|c|c|}
\hline \multirow[b]{3}{*}{$\begin{array}{l}\text { Patient and } \\
\text { treatment }\end{array}$} & & & \multicolumn{4}{|c|}{$\begin{array}{l}\text { Immunohistochemical } \\
\text { IgG epidermal score }\end{array}$} \\
\hline & \multicolumn{2}{|c|}{$\begin{array}{l}\text { IgG blister fluid } \\
\text { concentration (g/l) }\end{array}$} & \multicolumn{2}{|c|}{ On admission } & \multicolumn{2}{|c|}{ After 3 days } \\
\hline & $\begin{array}{l}\text { On } \\
\text { admission }\end{array}$ & $\begin{array}{l}\text { After } \\
3 \text { days }\end{array}$ & Blister & $\begin{array}{l}\text { Intact } \\
\text { skin }\end{array}$ & Blister & $\begin{array}{l}\text { Intact } \\
\text { skin }\end{array}$ \\
\hline 4-IVlg & 3.57 & 10.5 & 4 & 3 & 4 & 3 \\
\hline 6-IVIg & 2.99 & 11.9 & 1 & 1 & 4 & 4 \\
\hline 7-untreated & 1.34 & 0.89 & 2 & 2 & 2 & 2 \\
\hline 11-untreated & 0.63 & 2.15 & 2 & 1 & 2 & 1 \\
\hline
\end{tabular}


the epidermal blister roof $(2,3)$ than in uninvolved skin $(1,7)$ in the IVIg-treated patients. The same finding was evidenced in the control groups (2.6 vs. 1.8). In the IVIg group, the IgG mean score raised significantly and equally at the completion of the treatment, both in TENdamaged epidermis (2.3 vs. 3.7) (Fig. 1a,b) and in uninvolved skin (1.7 vs. 3.7). In the control group, there was nearly no change in the $\mathrm{IgG}$ mean score in the blister epidermis (2.6 vs. 2.6) or uninvolved skin (1.8 vs. 2.0) (Table 5).

\section{Correlation between $\operatorname{Ig} G$ blister fluid concentration and immunohistochemical rating}

Although only examined in four patients, a correlation between $\operatorname{IgG}$ blister fluid concentration and $\operatorname{IgG}$ immunohistochemical score was suggested both in IVIg-treated and in untreated TEN-involved epidermis after 3 days. This correlation seemed also likely in uninvolved skin
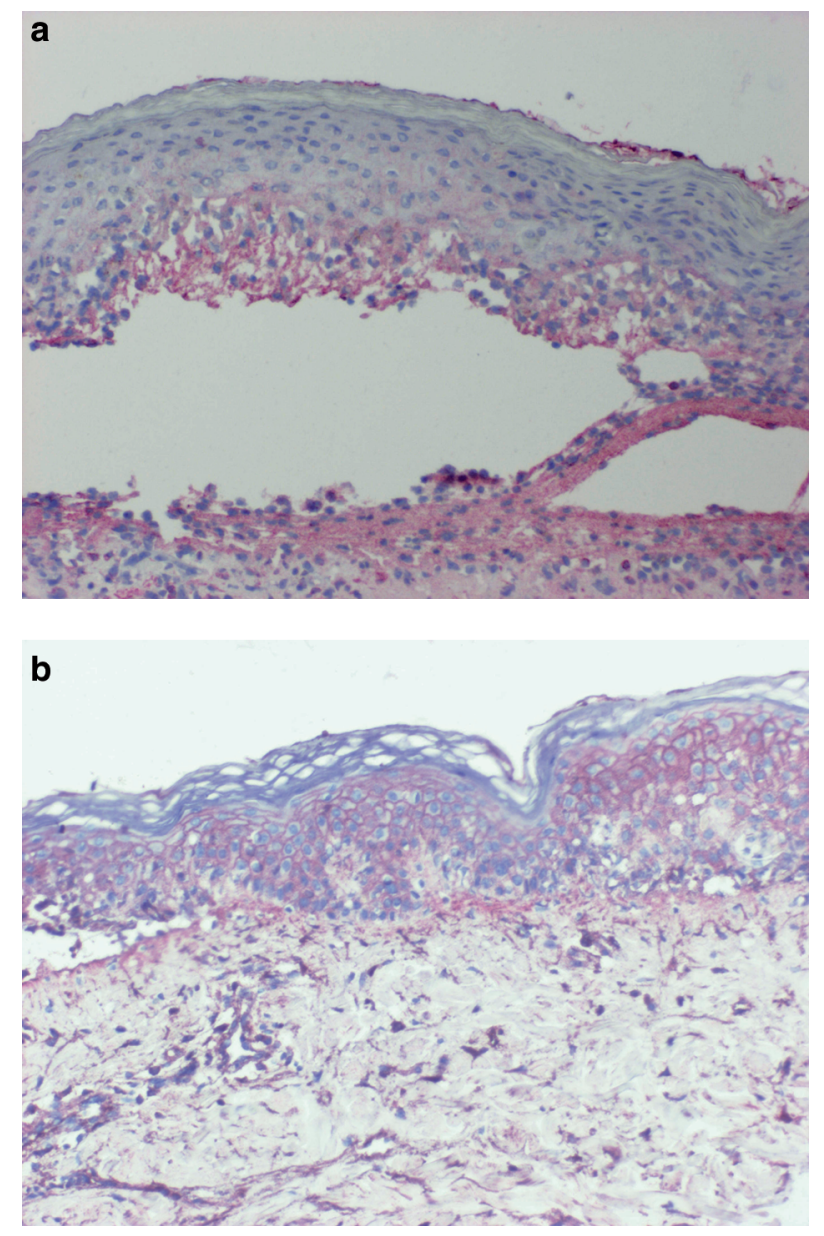

Figure 1. IgG pemphigus-like epidermal deposits before (a) and after (b) a 3-day intravenous immunoglobulin (IVIg) treatment in a toxic epidermal necrolysis (TEN) patient. A marked increase in immunolabeling is shown.
(Table 4). In the IVIg group, the mean increase in epidermal Ig staining was mainly due to case 6 as case 4 had already intense staining at onset. Moreover, the mean value could be somewhat misleading given that only two cases were studied for this parameter.

\section{Discussion}

The composition of the blister fluid in TEN has not been thoroughly explored so far. Among other bioactive molecules, we presently show that TEN blister fluid contains Ig, especially IgG. In each TEN patient, the Ig content in serum was significantly higher than in the blister fluid. Thus, it is inferred that the TEN blister fluid is a transudate (18). When the TEN epidermis is altered, the permeability of the postcapillary venules may be increased in the upper dermis (19). Some cytokines such as TNF- $\alpha$ (4) and ROS (20) including NO have been shown to be potential mediators in TEN pathophysiology. They are also potent vasodilators (21). The formation of small interendothelial pores is associated with increased permeability, and plasma is driven through these pores into the extravascular space. Extravasated plasma causes its own epithelial passage by mechanisms involving an increased basolateral pressure load on the epithelial cells (19).

Commercially available IVIg preparations consist of intact IgG with a distribution of IgG subclasses similar to the normal human serum (7). Most preparations contain minute amounts of IgA and IgM (7). Indeed, the IVIg-treated TEN patients showed a large increase in $\mathrm{IgG}$ content

Table 5. Scoring of immunoglobulin $(\mathrm{g})$ deposits in the epidermis

\begin{tabular}{|c|c|c|c|c|}
\hline \multirow[b]{2}{*}{ Patients } & \multicolumn{2}{|l|}{ At baseline } & \multicolumn{2}{|c|}{3 days of evolution } \\
\hline & Involved skin & Intact skin & Involved skin & Intact skin \\
\hline \multicolumn{5}{|c|}{ IVIg treated } \\
\hline 1 & 4 & 3 & 3 & 3 \\
\hline 2 & 1 & 1 & 3 & 4 \\
\hline 3 & 1 & 1 & 4 & 4 \\
\hline 4 & 4 & 3 & 4 & 3 \\
\hline 5 & 3 & 1 & 4 & 4 \\
\hline 6 & 1 & 1 & 4 & 4 \\
\hline Mean & 2.3 & 1.7 & 3.7 & 3.7 \\
\hline \multicolumn{5}{|l|}{ Controls } \\
\hline 7 & 2 & 2 & 2 & 2 \\
\hline 8 & 3 & 2 & 3 & 2 \\
\hline 9 & 3 & 3 & 4 & 4 \\
\hline 10 & 3 & 1 & 2 & 1 \\
\hline 11 & 2 & 1 & 2 & 1 \\
\hline Mean & 2.6 & 1.8 & 2.6 & 2.0 \\
\hline
\end{tabular}


in serum at the completion of the treatment, while $\operatorname{IgA}$ and IgM contents remained unmodified. In TEN control patients, the serum IgG concentration remained grossly unchanged after 3 days of evolution of the disease, ruling out any increased Ig supply by the patient him/herself.

The large difference in the IgG serum concentrations in the TEN-treated and control groups at baseline could be ascribed to the storage conditions of the biological samples. Indeed, the integrity of the Ig stored at $-20^{\circ} \mathrm{C}$ is only guaranteed for up to 1 year. Over this conservation time, the in vitro quantitative determination of the Ig may be impaired. Such a degradation probably occurred in the samples of the untreated patients which were stored for 4-6 years.

In IVIg-treated TEN patients, the concentration of $\operatorname{IgG}$, but not of $\operatorname{IgA}$ and $\operatorname{IgM}$, increased considerably in the blister fluid at the completion of IVIg perfusions. In TEN control patients, no difference was observed in Ig blister fluid concentrations. This suggests that IVIg administration is followed by an increase in supplemented $\mathrm{IgG}$ concentration in TEN blister fluid. This represents the basic condition to benefit from the therapeutic effect with the IVIg preparation in TEN. In TEN, IVIg has been shown to inhibit Fas (CD95)-mediated cell death by blocking the Fas receptor rather than interacting with Fas ligand (6). IVIg contains both agonistic and blocking antibodies against CD95 receptor, thus modulating the transduction of apoptotic signals into cells $(6,7)$. However, there are great variations in Fas- $\mathrm{R}$ inhibitory activity due to differences in anti-Fas antibody content within IVIg batches (11).

This immunohistochemical findings indicate that IgG are present in TEN-involved and in clinically uninvolved skin. After IVIg perfusion, IgG deposits greatly and equally increase in TEN-involved and uninvolved skin, indicating that $\operatorname{IgG}$ exudation takes place everywhere in the epidermis irrespective of the presence of necrotic keratinocytes. The increase in IgG content in clinically TEN-uninvolved skin after IVIg may carry protective effect in these areas, preventing any progression of the epidermal destruction. In control TEN patients, Ig deposits in the epidermis remained low and unchanged after 3 days, also indicating that IVIg perfusions permit to increase Ig concentration in TEN skin.

Moreover, a correlation is suggested between IgG concentrations in lesion fluids and IgG epidermal deposits. As previously reported in TEN prominent Ig deposits exhibited a pemphigus-like pattern, suggesting a possible fixation to the cytoplasmic membrane of the keratinocytes $(22,23)$. However, the exact cytoplasmic molecules to which IgG bind in TEN epidermis are unknown.

In conclusion, IVIg perfusion in TEN patients resulted in a large increase in IgG concentration in serum, blister fluid and epidermis in necrotic and clinically uninvolved skin. This represents the necessary condition to get a protective effect of IVIg, especially by carrying blocking antibodies against FasR in the skin. The presence of potentially protective IgG in clinically uninvolved TEN skin could have some beneficial effect on the necrosis progression in these areas.

\section{Acknowledgements}

This work was supported by a grant from the Fonds d'Investissement de la Recherche Scientifique of the University Hospital of Liège, Belgium.

\section{References}

1. Paquet P, Piérard G E, Quatresooz P. Novel treatments for drug-induced toxic epidermal necrolysis (Lyell's syndrome). Int Arch Allergy Immunol 2005: 136: 205-216.

2. Abe R, Shimizu T, Shibaki A, Nakamura H, Watanabe H, Shimizu H. Toxic epidermal necrolysis and StevensJohnson syndrome are induced by soluble Fas ligand. Am J Pathol 2003: 162: 1515-1520.

3. Nassif A, Bensussan A, Boumsell L et al. Epidermal necrolysis: effector cells are drug-specific cytotoxic $\mathrm{T}$ cells. J Allergy Clin Immunol 2004: 114: 1209-1215.

4. Paquet P, Nikkels A, Arrese J E, Vanderkelen A, Piérard G E. Macrophages and tumor necrosis factoralpha in toxic epidermal necrolysis. Arch Dermatol 1994: 130: 605-608.

5. Herndon D N. Toxic epidermal necrolysis: a systemic and dermatologic disorder best treated with standard treatment protocols in burn intensive care units without the prolonged use of corticosteroids. J Am Coll Surg 1995: 180: 340-342.

6. Viard I, Wehrli P, Bullani R et al. Inhibition of toxic epidermal necrolysis by blockade of CD95 with human intravenous immunoglobulin. Science 1998: 282: 490-493.

7. Kazatchkine M D, Kaveri S V. Immunomodulation of autoimmune and inflammatory diseases with intravenous immune globulin. N Engl J Med 2001: 345: 747-755.

8. Stella M, Cassano P, Bollero D, Clemente A, Giorio G. Toxic epidermal necrolysis treated with intravenous high-dose immunoglobulins: our experience. Dermatology 2001: 203: 45-49.

9. Paquet P, Jacob E, Damas P, Piérard G E. Treatment of drug-induced toxic epidermal necrolysis (Lyell's syndrome) with intravenous human immunoglobulins. Burns 2001: 27: 652-655.

10. Tristani-Firouzi P, Petersen M, Saffle J R, Morris S, Zone J. Treatment of toxic epidermal necrolysis with 


\section{Paquet et al.}

intravenous immunoglobulin in children. J Am Acad Dermatol 2002: 47: 548-552.

11. Prins C, Kerdel F A, Padilla R S, et al. Treatment of toxic epidermal necrolysis with high-dose intravenous immunoglobulins. Arch Dermatol 2003: 139: 26-32.

12. Bachot N, Revuz J, Roujeau J C. Intravenous immunoglobulin treatment for Stevens-Johnson syndrome and toxic epidermal necrolysis. Arch Dermatol 2003: 139: 33-36.

13. Trent J T, Kirsner R S, Romanelli P, Kerdel F A. Analysis of intravenous immunoglobulin for the treatment of toxic epidermal necrolysis using SCORTEN. Arch Dermatol 2003: 139: 39-43.

14. Bastuji-Garin S, Rzany B, Stern R S, Shear N H, Naldi L, Roujeau J C. Clinical classification of cases of toxic epidermal necrolysis, Stevens-Johnson syndrome, and erythema multiforme. Arch Dermatol 1993: 129: 92-96.

15. Dati F, Schumann G, Thomas L, et al. Consensus of a group of professional societies and diagnostic companies on guidelines for interim reference ranges for 14 proteins in serum based on the standardization against the IFCC/BCR/CAP reference material (CRM470). Eur J Clin Chem Clin Biochem 1996: 34: 517-520.

16. Arrese J E, Ben Mosbah T, Piérard-Franchimont C, Deleixhe-Mauhin F, Piérard G E. Importancia diagnostica de los depositos de inmunoglobulinas y complemento en afectiones cutaneas: nuevas tecnicas y perspectivas. Med Cutan Ibero Lat Am 1993: 21: 131-135.
17. Quatresooz P, Fumal I, Willemaers V, Cornil F, Piérard G E. Diffuse dermal angiomatosis: undescribed pattern of immunoglobulin and complement deposits in two cases. Am J Dermatopathol (in press).

18. Gouteux-Frezzotti D, Bolard F, Ramon $\mathrm{P} H$, Steenhouwer F. Etude de différents critères biologiques permettant de distinguer les exsudats pleuraux des transsudats. Rev Pneumol Clin 2002: 58: 11-16.

19. Persson C G A, Erjefalt J S, Greiff L, et al. Plasmaderived proteins in airway defence, disease and repair of epithelial injury. Eur Respir J 1998: 11: 958-970.

20. Lerner L H, Qureshi A A, Reddy B V, Lerner E A. Nitric oxide synthase in toxic epidermal necrolysis and Stevens-Johnson syndrome. J Invest Dermatol 2000: 114: 196-199.

21. Perez A C, Khawaja A M, Page C P, Paul W. Persistence of effects of nitric oxide synthase inhibitors: comparisons on blood flow and plasma exudation in guinea pig skin. Eur J Pharmacol 1997: 330: 241-246.

22. Stein K, Schlappner O, Heaton C, Decherd J. Demonstration of basal cell immunofluorescences in drug-induced toxic epidermal necrolysis. $\mathrm{Br} \quad \mathrm{J}$ Dermatol 1972: 86: 246-252.

23. Hensen E J, Claas F H J, Vermeer B J. Drugdependent binding of circulating antibodies in druginduced toxic epidermal necrolysis. Lancet 1981: ii: $151-152$. 